\title{
VALIDATED STABILITY INDICATING RP-HPLC METHOD FOR SIMULTANEOUS DETERMINATION OF NORTRIPTYLINE AND PREGABALIN IN BULK AND COMBINED DOSAGE FORMULATIONS
}

\author{
HARITHA POTLURI I, , SREENIVASA RAO BATTULA², SUNANDAMMA YETURU \\ ${ }^{1}$ Department of Chemistry, JNTUK, Kakinada, India. \\ ${ }^{2}$ Department of Chemistry, GITAM University, Visakhapatnam, India. \\ ${ }^{3}$ Department of Chemistry, Acharya Nagarjuna University, Nagarjuna Nagar, India.
}

\begin{abstract}
A simple and precise stability indicating RP-HPLC method was developed for simultaneous analysis of drug nortriptyline and pregabalin using BDS (250mm $\mathrm{x} 4.6 \mathrm{~mm}, 5 \mu) \mathrm{C} 18$ column at $210 \mathrm{~nm}$ of UV detection. Perchloric acid $(0.1 \%)$ and acetonitrile in the ratio of 55:45 was used as the mobile phase with a flow rate of $1.0 \mathrm{ml} / \mathrm{min}$ and linearity response was established over the concentration range of $5-30 \mu \mathrm{g} / \mathrm{ml}$ for nortriptyline and $37.5-225 \mu \mathrm{g} / \mathrm{ml}$ for pregabalin. The active pharmaceutical ingredients recovered for nortriptyline and pregabalin are in the range of $100.60-101.65 \%$ and $100.59-101.74 \%$ respectively. The method was validated and was found to be stability indicating and can be successfully utilized for the quantitative analysis of pharmaceutical tablet dosage formulations containing nortriptyline and pregabalin.
\end{abstract}

Keywords: nortriptyline, pregabalin, HPLC, stability indicating, validation.

\section{INTRODUCTION}

Nortriptyline (NOR) comes under the class of tri cyclic antidepressant. It is used to treat depression, panic disorders and to help people to quit the smoking (1). It is chemically 3-(10, 11-Dihydro-5H-dibenzo [a, d] cyclohepten-5ylidene)-N-methyl-1-propanamine (2) (Figure 1)

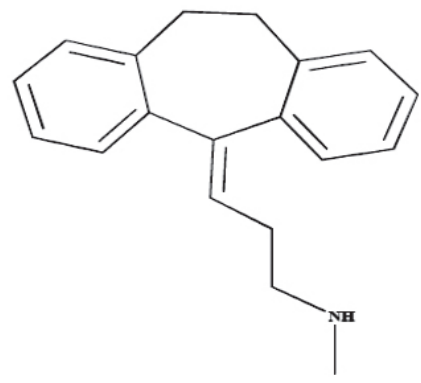

Figure 1 Chemical structure of NOR

Pregabalin (PRE) comes under the class of anticonvulsant in medical terminology. It decreases the number of pain signals that are sent by damaged nerves in the human body thereby relieving the pain (3). It is chemically (S)-3(amino methyl)-5-methylhexanoic acid (4) (Figure 2).

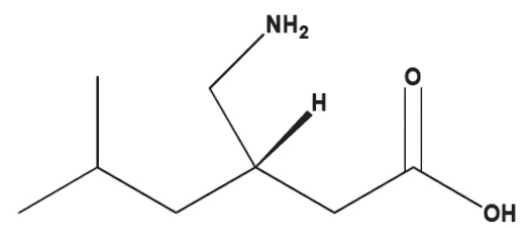

Figure 2 Chemical structure of PRE

The tablet containing the combination of NOR and PRE is used effectively as an antidepressant, anticonvulsant and to overcome neuropathic pain.

The changes that occur in physical, chemical, or microbiological properties of the drug over a passage of time period can be predicted using a quantitative analytical method. A specific validated method is evolved to measure the content precisely, of the active ingredient of the drug without interference, and to measure the same after degradation which is termed as the stability indicating method (5). Stability testing gives the information of various degradation mechanisms, possible degradation products, pathways ascertaining probable degradation of the drug, and also the interaction involving the drug and the excipients in drug product (6). Literature survey has revealed the spectroscopic method for analysis of NOR(7).Combination of NOR with fluphenazine hydrochloride drug was analyzed using HPLC method(8).HPLC methods for the determination of PRE(9) and the combination of PRE with other drugs(10-13) are also available. From the literature, it is evident that no analytical method has been reported for simultaneous analysis of NOR and PRE in a tablet and the aim of the present investigation is to develop a simple, precise, consistent, accurate, selective and sensitive RP-HPLC method indicating stability for the analysis of NOR and PRE that can be applied for a bulk drug as well as combined drug tablet formulation.

\section{EXPERIMENTAL}

The analytical quality samples of NOR (99.88\%) and PRE (99.68\%) were received from Spectrum Pharmacy, Hyderabad, India as gift samples. Tablets of NOR and PRE are procured from the local stores. Milli-Q water, HPLC grade perchloric acid, methanol and acetonitrile are purchased from Merck Ltd., India.

Instrumentation and chromatographic conditions

The chromatographic separation was done on Waters HPLC, which is incorporated with an auto sampler and UV detector. BDS $(250 \mathrm{~mm} \times 4.6 \mathrm{~mm}$, $5 \mu) \mathrm{C} 18$ column is used for the chromatographic separation. Perchloric acid $(0.1 \%)$ and acetonitrile in the ratio of 55:45 was utilized as the mobile phase. The freshly prepared mobile phase was filtered and sonicated prior to use and was delivered at a flow rate of $1.0 \mathrm{ml} / \mathrm{min}$ by setting the wavelength of detection at $210 \mathrm{~nm}$. The volume of injection taken was $10 \mu \mathrm{L}$. The column temperature was maintained at $30{ }^{0} \mathrm{C}$. The diluent used for preparing drug solution was methanol along with water: acetonitrile, in the composition ratio of 50:50. Data was gathered by using the Empower 2 software.

Preparation of standard solution of NOR and PRE

Accurately weighed $5 \mathrm{mg}$ of NOR and $37.5 \mathrm{mg}$ of PRE (AR grade) were transferred into two separate clean and dry, $25 \mathrm{ml}$ volumetric flasks. About $15 \mathrm{ml}$ of diluent was added in each of the flask, sonicated for about a period of 30 minutes and made up to the final volume with the diluents. One $\mathrm{ml}$ each of the above stock solutions was transferred with the help of a pipette into a $10 \mathrm{ml}$ volumetric flask and then made up to the final volume by using the diluents.

Preparation of sample solution of NOR and PRE

Twenty tablets of NOR $10 \mathrm{mg}$ and PRE $75 \mathrm{mg}$ / tablet (as the labeled claim) are taken and powdered very finely. Accurately weighed sample containing NOR $10 \mathrm{mg}$ and PRE $75 \mathrm{mg}$ was then transferred into a clean and dry 50 $\mathrm{ml}$ volumetric flask and about $25 \mathrm{ml}$ of diluent was added and sonicated to dissolve the material completely and made up to the mark by using the diluents and labeled as sample stock solution. This was filtered by using the HPLC filters and then one $\mathrm{ml}$ of filtered sample stock solution was transferred to a 10 $\mathrm{ml}$ volumetric flask and made up to the mark by using the diluents.

The standard and sample solution of NOR and PRE of volume $10 \mu \mathrm{l}$ are 
made to inject into the chromatographic system and from the values of obtained peak areas, the assessment of $\%$ assay was done.

\section{RESULTS AND DISCUSSION}

In the literature, there is no reported HPLC method for simultaneous determination of NOR and PRE. So, the main aim of this study was to develop a specific, precise, accurate, sensitive, robust, reproducible and reliable HPLC method to estimate NOR and PRE in a short run time and can be used in quality control laboratories.

Optimization of chromatographic conditions

Different trials are performed by taking different compositions of the mobile phase such as Perchloric acid $(0.1 \%)$ and acetonitrile in the ratio of $30: 70,40: 60,20: 80$, but the peaks obtained are not clear and are unsymmetrical. Trials are also performed by taking different mobile phases like methanol and water, acetonitrile and water and also tried various columns like Kromosil 250, BDS 250 , Symmetry C18 and Kromosil 8 but could not get satisfactory peaks. Different extraction methods were optimized for extraction of NOR and PRE from the tablet matrix and good recovery was obtained using methanol along with water: acetonitrile, in the composition ratio of 50:50. A good separation and elution were achieved using perchloric acid $(0.1 \%)$ and acetonitrile in the ratio of 55:45 was used as the mobile phase with a flow rate of $1.0 \mathrm{ml} / \mathrm{min}$. BDS $(250 \mathrm{~mm} \times 4.6 \mathrm{~mm}, 5 \mu) \mathrm{C} 18$ column at $210 \mathrm{~nm}$ of UV detection.

The validation parameters for the proposed analytical method are elucidated as per the guidelines of ICH (14). The achieved validation parameters are encapsulated in Table 1.

Table 2 Recovery studies of NOR and PRE.
Table 1 Analytical validation parameters (system suitability and linearity).

\begin{tabular}{|c|c|c|}
\hline Parameter & NOR & PRE \\
\hline Linearity & $5-30 \mu \mathrm{g} / \mathrm{ml}$ & $37.5-225 \mu \mathrm{g} / \mathrm{ml}$ \\
\hline Slope & 7430.2 & 7581.8 \\
\hline Intercept & 530.86 & 1744.7 \\
\hline Coefficient of correlation & 0.9993 & 0.9998 \\
\hline LOD & $0.1048 \mu \mathrm{g} / \mathrm{ml}$ & $0.3697 \mu \mathrm{g} / \mathrm{ml}$ \\
\hline LOQ & $0.3176 \mu \mathrm{g} / \mathrm{ml}$ & $1.1205 \mu \mathrm{g} / \mathrm{ml}$ \\
\hline Theoretical Plates & 5159 & 10667 \\
\hline Tailing Factor & 1.14 & 1.21 \\
\hline Retention Time (min) & 2.543 & 4.242 \\
\hline
\end{tabular}

Linearity

The linearity for the proposed HPLC method was established at six concentration levels by least squares linear regression method that represented no significant linearity deviation.

Recovery

Known concentrations for three different samples that range from 5-30 $\mu \mathrm{g} / \mathrm{ml}$ for NOR and $37.5-225 \mu \mathrm{g} / \mathrm{ml}$ for PRE are prepared and the analysis was done against standard solution. The obtained results are represented in Table 2.

\begin{tabular}{|c|c|c|c|c|c|}
\hline \multicolumn{6}{|c|}{ Recovery data of NOR } \\
\hline $\begin{array}{c}\text { Concentration } \\
\text { (at specified level) }\end{array}$ & $\begin{array}{l}\text { Peak } \\
\text { area }\end{array}$ & $\begin{array}{l}\text { Amount Added } \\
\text { in } \mu \mathrm{g}\end{array}$ & $\begin{array}{l}\text { Amount Found } \\
\text { in } \mu \mathrm{g}\end{array}$ & $\%$ recovered & $\begin{array}{c}\text { Mean } \\
\text { \% Recovery }\end{array}$ \\
\hline $50 \%$ & 224045 & 10 & 10.06 & 100.60 & \multirow{3}{*}{101.09} \\
\hline $100 \%$ & 303389 & 20 & 20.33 & 101.65 & \\
\hline $150 \%$ & 374649 & 30 & 30.31 & 101.04 & \\
\hline \multicolumn{6}{|c|}{ Recovery data of PRE } \\
\hline $\begin{array}{c}\text { Concentration } \\
\text { (at specified level) }\end{array}$ & $\begin{array}{l}\text { Peak } \\
\text { area }\end{array}$ & $\begin{array}{l}\text { Amount added } \\
\text { in } \mu \mathrm{g}\end{array}$ & $\begin{array}{l}\text { Amount found } \\
\text { in } \mu \mathrm{g}\end{array}$ & $\%$ recovered & $\begin{array}{c}\text { Mean } \\
\% \text { Recovery }\end{array}$ \\
\hline $50 \%$ & 1716899 & 75 & 75.98 & 101.31 & \multirow{3}{*}{101.21} \\
\hline $100 \%$ & 2298646 & 150 & 152.60 & 101.74 & \\
\hline $150 \%$ & 2858337 & 225 & 226.32 & 100.59 & \\
\hline
\end{tabular}

Precision

Evaluation of the precision of the method was done by testing six samples of marketed dose. For study of the intermediate precision, the same analyst was made to conduct the experiment on different days for six samples of marketed dose. Small deliberate changes in mobile phase and flow rate are made for establishing the robustness of the method. From the obtained low value of relative standard deviation, it was obvious that the proposed method was not affected much by the changes which in turn prove the ruggedness and robustness of the developed method. The Intra-day and Inter-day results for precision analysis are elucidated in Table 3. The tablet dosage formulation assay results that are obtained by the proposed method are presented in Table 4.

Table 3 Intra-day and inter-day precision analysis of NOR and PRE.

\begin{tabular}{|c|c|c|c|c|c|}
\hline \multirow{2}{*}{ Drug } & \multirow{2}{*}{ Concentration $(\boldsymbol{\mu g} / \mathbf{m l})$} & \multicolumn{2}{|c|}{ Intra-day precision } & \multicolumn{2}{c|}{ Inter-day precision } \\
\cline { 3 - 6 } & & SD & \%RSD & SD & \%RSD \\
\hline NOR & 10 & 1066.4 & 0.7 & 635.1 & 0.4 \\
\hline PRE & 75 & 7398 & 0.6 & 3910.9 & 0.3 \\
\hline
\end{tabular}

Table 4 Assay result of tablet dosage form

\begin{tabular}{|c|c|c|c|}
\hline Drug & Label strength in mg & Amount found in mg & \% Assay \\
\hline NOR & 10 & 10.03 & 100.32 \\
\hline PRE & 75 & 75.39 & 100.53 \\
\hline
\end{tabular}

Sensitivity 
The lowest concentration level of the drug that gives response is said as limit of detection (LOD). The lowest concentration level that could be analyzed with accuracy by the proposed RP-HPLC method is termed as limit of quantification (LOQ). The values found for the limit of detection (LOD) and limit of quantification (LOQ) are $0.1048 \mu \mathrm{g} / \mathrm{ml}$ and $0.3176 \mu \mathrm{g} / \mathrm{ml}$ for NOR and $0.3697 \mu \mathrm{g} / \mathrm{ml}$ and $1.1205 \mu \mathrm{g} / \mathrm{ml}$ for PRE. The LOD and LOQ obtained showed the sensitivity of the method for NOR and PRE.

Stability

For the purpose of indicating the stability of both standard and sample solutions during the analysis period, both solutions are tested for a time period of $24 \mathrm{hr}$ at room temperature. The analysis revealed that no considerable degradation has occurred as the retention time and peak area of NOR and PRE remained almost undisturbed (as \% R.S.D. is less than 2.0) that indicates stability for a period of $24 \mathrm{hr}$ for both the solutions which was adequate to complete the entire analytical procedure.
System suitability test

The specificity of the present proposed method can be judged by complete separation of NOR and PRE as was depicted in Figure 3 with parameters such as resolution, retention time and tailing factor. The tailing factor for peaks of NOR and PRE was found to be less than $2 \%$ and the resolution was excellent. The peaks obtained for NOR and PRE were observed to be sharp and have a noticeable baseline separation. The mean retention time for six replicate samples of NOR and PRE was found to be 2.539 and 4.238 minutes respectively. Analysis was performed both at stressed and unstressed factors for active NOR and PRE, placebo sample (containing all the ingredients except active NOR and PRE) and from this analysis, there was no interference of peak in the NOR and PRE region for the stressed, placebo and active sample. Hence it is concluded that the developed method was specific for the analysis of this drug.

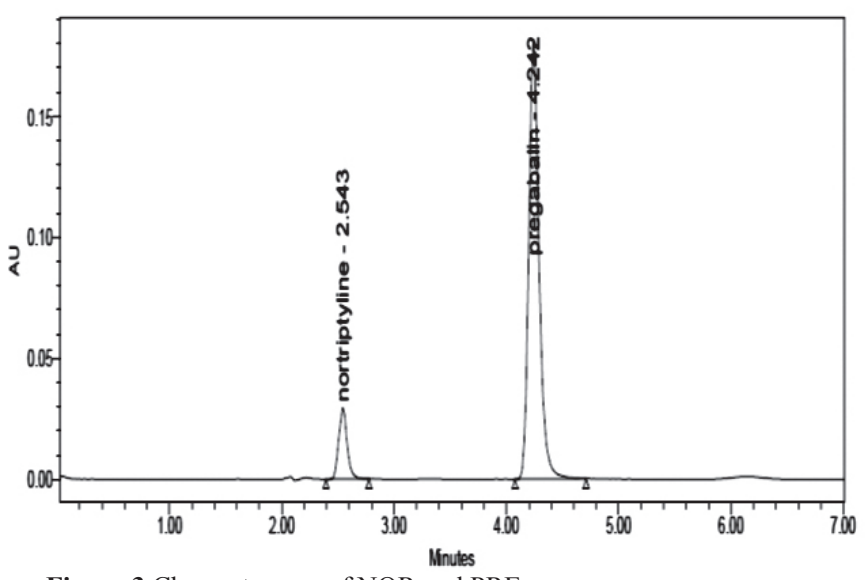

Figure 3 Chromatogram of NOR and PRE

Forced degradation studies

Forced degradation studies are done for indicating the stability of the developed method. The degradation studies results are predicted in Table 5 .

Table 5 Forced degradation studies of NOR and PRE.

\begin{tabular}{|c|c|c|c|c|c|c|c|}
\hline \multirow[t]{2}{*}{ Stress Conditions } & \multirow{2}{*}{ Degradation Time } & \multicolumn{2}{|c|}{ Peak Area } & \multicolumn{2}{|c|}{ Degradation \% } & \multicolumn{2}{|c|}{$\begin{array}{c}\text { active drug } \% \text { present after } \\
\text { degradation }\end{array}$} \\
\hline & & NOR & PRE & NOR & PRE & NOR & PRE \\
\hline Control & & 153175 & 1154799 & & & & \\
\hline acid & $30 \mathrm{~min}$ & 144493 & 1115181 & 5.67 & 3.44 & 94.33 & 96.56 \\
\hline alkali & $30 \mathrm{~min}$ & 145024 & 1131829 & 5.33 & 1.99 & 94.67 & 98.01 \\
\hline oxidative & $30 \mathrm{~min}$ & 142916 & 1113741 & 6.7 & 3.56 & 93.30 & 96.44 \\
\hline thermal & 6 hours & 152057 & 1148298 & 0.73 & 0.57 & 99.27 & 99.43 \\
\hline photo & 7 days & 152108 & 1148517 & 0.70 & 0.55 & 99.30 & 99.45 \\
\hline
\end{tabular}

Control sample

Twenty tablets of which the labeled claim is NOR $10 \mathrm{mg}$ and PRE 75 mg / tablet are taken and powdered very finely. Accurately weighed sample containing NOR $10 \mathrm{mg}$ and PRE $75 \mathrm{mg}$ was transferred into a $50 \mathrm{ml}$ clean and dry volumetric flask and about $25 \mathrm{ml}$ of diluent was added and sonicated to dissolve it completely and made up to the mark by using the diluents. This freshly prepared solution was filtered by using the HPLC filters and was labeled as control sample. Then $1 \mathrm{ml}$ of filtered control sample solution was transferred to a $10 \mathrm{ml}$ volumetric flask and made up to the mark with diluents to obtain 20 $\mu \mathrm{g} / \mathrm{ml}$ of NOR and $150 \mu \mathrm{g} / \mathrm{ml}$ of PRE solution. A measured quantity $(10 \mu \mathrm{L})$ of this solution was injected to obtain the chromatogram.

Acid degradation studies

To $1 \mathrm{ml}$ of control sample of NOR and PRE, $1 \mathrm{ml}$ of $2 \mathrm{~N}$ Hydrochloric acid was added. It was then refluxed for 30 minutes at $60^{\circ} \mathrm{C}$ and the solution was then diluted to obtain $20 \mu \mathrm{g} / \mathrm{ml}$ of NOR and $150 \mu \mathrm{g} / \mathrm{ml}$ of PRE. This solution of volume $10 \mu \mathrm{l}$ was injected into the system and the chromatograms are recorded to study the stability of sample to acid degradation. The obtained chromatogram for acid degradation was given in Figure 4.

Alkali degradation studies

To $1 \mathrm{ml}$ of control sample of NOR and PRE, $2 \mathrm{~N}$ sodium hydroxide of volume $1 \mathrm{ml}$ was added and then refluxed for 30minutes at a temperature of $60^{\circ} \mathrm{C}$. The solution was then diluted to obtain $20 \mu \mathrm{g} / \mathrm{ml}$ of NOR and $150 \mu \mathrm{g}$ $\mathrm{ml}$ of PRE solution. Then a $10 \mu 1$ volume of this solution was then injected into the chromatographic system and the recording of chromatograms was done to analyze the stability of sample to alkali degradation condition. The chromatogram obtained for alkali degradation was depicted in Figure 5. 


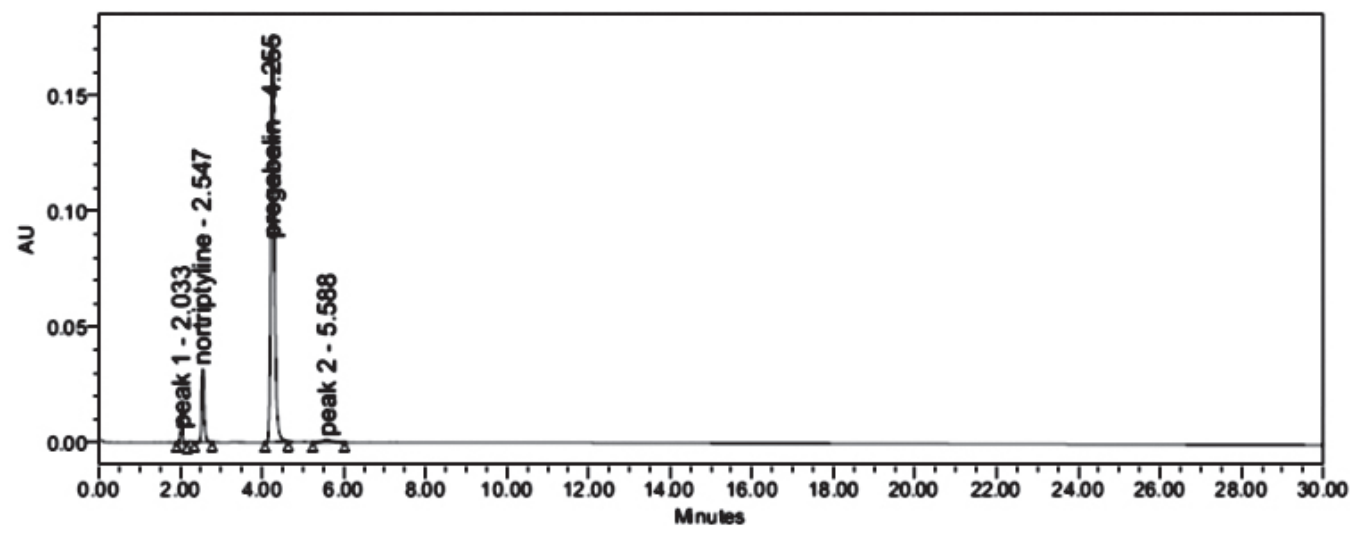

Figure 4 Acid degradation studies chromatogram of NOR and PRE

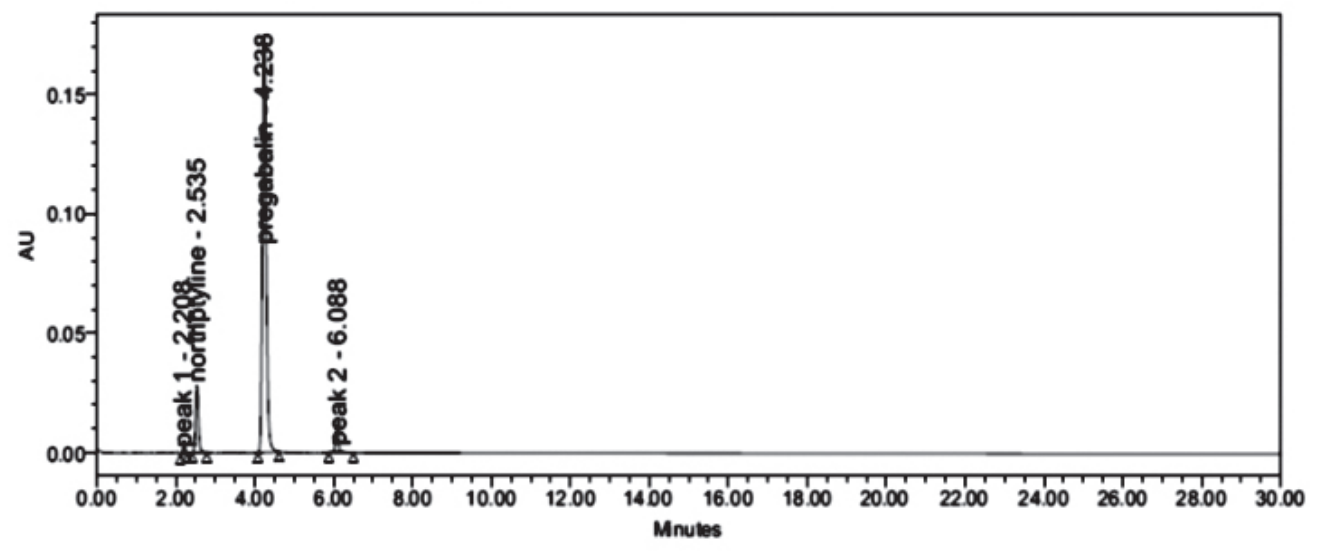

Figure 5 Alkali degradation studies chromatogram of NOR and PRE

Oxidative degradation studies

To $1 \mathrm{ml}$ of control sample of NOR and PRE, $1 \mathrm{ml}$ of Hydrogen peroxide $\left(\mathrm{H}_{2} \mathrm{O}_{2}\right)$ of strength $20 \%$ was added .The solution was exposed to a temperature of $60^{\circ} \mathrm{C}$ for a period of $30 \mathrm{mins}$. Dilution of the solution was made to get $20 \mu \mathrm{g} / \mathrm{ml}$ of NOR and $150 \mu \mathrm{g} / \mathrm{ml} \mathrm{of} \mathrm{PRE.} 10 \mu \mathrm{l}$ of this solution was then injected into the system and the chromatograms are recorded for the evaluation of stability of sample to alkali degradation condition. The chromatogram obtained for oxidative degradation was illustrated in Figure 6.

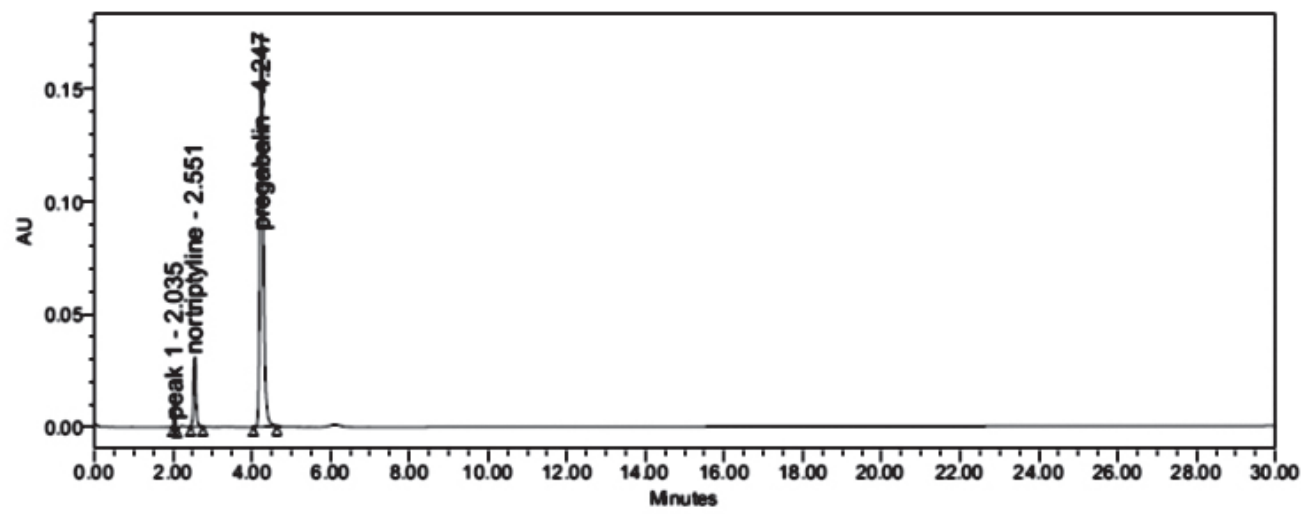

Figure 6 Oxidative degradation studies chromatogram of NOR and PRE

Thermal degradation studies

The control sample solution was placed in an oven at a temperature of 105 ${ }^{\circ} \mathrm{C}$ for period of about 6 hours for studying degradation stress due to heat. The solution was diluted to obtain $20 \mu \mathrm{g} / \mathrm{ml}$ of NOR and $150 \mu \mathrm{g} / \mathrm{ml}$ of PRE. Then a $10 \mu \mathrm{l}$ of this solution was injected into the system and the chromatograms are recorded for the evaluation of the stability of sample to thermal degradation condition. The chromatogram obtained for thermal degradation was illustrated in Figure 7. 


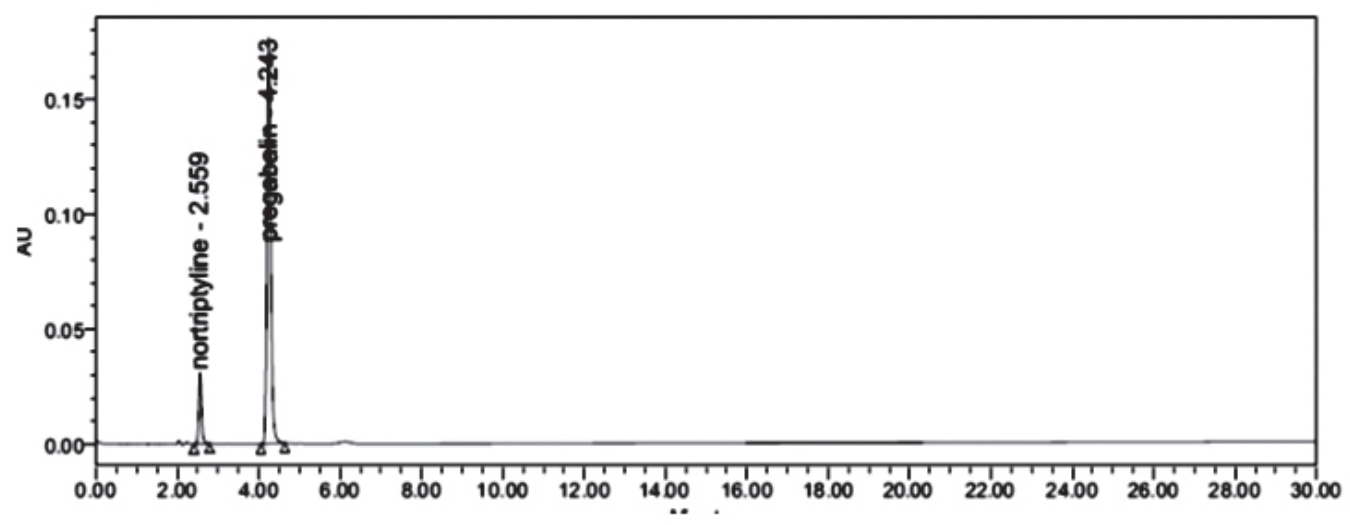

Figure 7 Thermal degradation studies chromatogram of NOR and PRE

\section{Photo degradation studies}

The photochemical stability of the drug was analyzed by exposing the solution containing $20 \mu \mathrm{g} / \mathrm{ml}$ of NOR and $150 \mu \mathrm{g} / \mathrm{ml}$ of PRE to UV light by placing the beaker in UV chamber for a period of 7 days. This solution of volume $10 \mu \mathrm{l}$ was injected into the system and the chromatograms are recorded for evaluating the stability of sample to UV degradation. The obtained chromatogram for photo degradation stress was given in Figure 8.

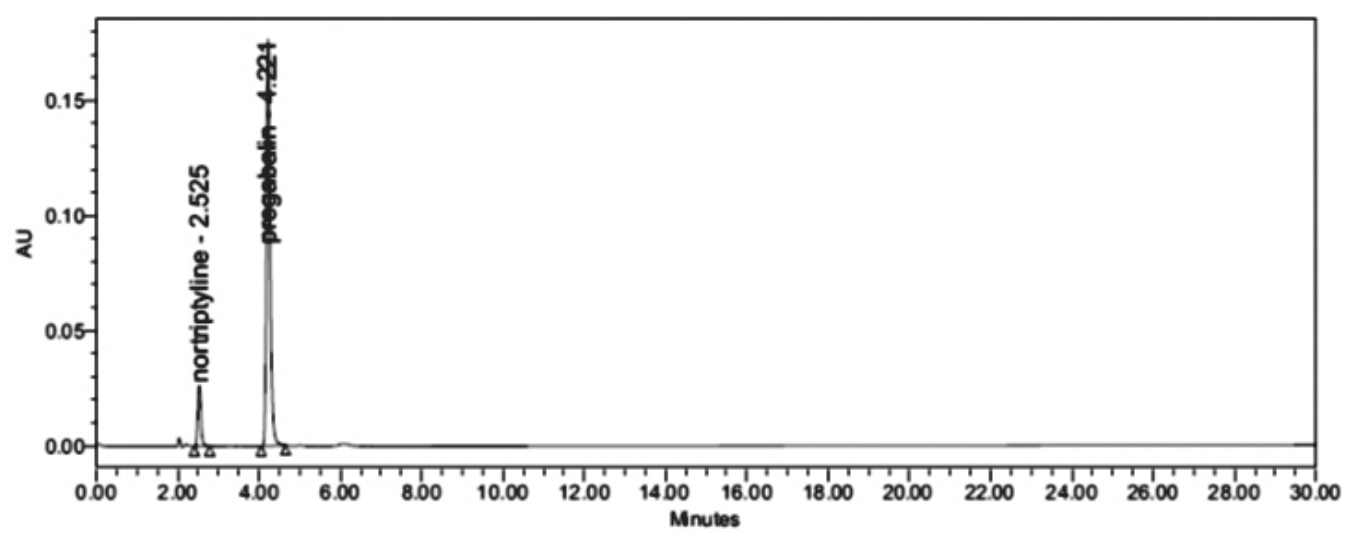

Figure 8 Photo degradation studies chromatogram of NOR and PRE

\section{CONCLUSION}

The present research investigation presents a simple and validated HPLC stability indicating method for simultaneous analysis of NOR and PRE in the presence of degradation products. The method developed was evaluated as specific, precise, accurate, sensitive, and robust. Very accurate and precise linear response was given by this method in the said range. The degradation products that are formed during the exposure of drug to stress conditions gave peaks that are well separated from that of the analyte peaks which establishes the fact that the developed method was specific and stability indicating. The developed method hence can be used for successful determination of marketed formulations containing NOR and PRE.

Financial support and sponsorship

$\mathrm{Nil}$

Conflicts of interest

The authors have none to declare.

\section{REFERENCES}

1. Gillman P K .Tricyclic antidepressant pharmacology and therapeutic drug interactions updated .Br. J. Pharmacol. 151, 737, (2007).

2. The British Pharmacopoeia, The Stationery Office, vol. 2, London, 2010; pp. 1295-1297.

3. Taylor CP, Angelotti T, Fauman E. Pharmacology and mechanism of action of pregabalin: The calcium channel alpha2-delta (alpha2-delta) subunit as a target for antiepileptic drug discovery. Epilepsy Res.73, 137, (2007).

4. Indian Pharmacopoeia, vol. 3, sixth edition, Ghaziabad, 2010; pp. 19601961.

5. Bakshi M, Singh S. Development of validated stability indicating assay methods- critical review. J Pharm Biomed Anal. 28, 1011, (2002).

6. Geneva: International Conference on Harmonization; ICH. QIA (R2) Harmonised Tripartite Guideline. Stability Testing of New Drug Substances and Products, 2003; pp. 1-18

7. Rahman H, Khatoon A, Rahman N. A validated kinetic method for determination of nortriptyline hydrochloride in pharmaceutical formulations. Int J Pharm Chem. 4, 99, (2014).

8. Ashour S, Kattan N. Simultaneous determination of nortriptyline hydrochloride and fluphenazine hydrochloride in microgram quantities from low dosage forms by liquid chromatography-UV detection. $J$ Pharm Anal. 2, 437, (2012).

9. Kasawar G B, Farooqui M N .Development and validation of HPLC method for the determination of Pregabalin in capsules.Indian J Pharm Sci. 72, 517, (2010).

10. Kannapan N, Nayak S P, Venkatachalam T, Prabhakaran V. Analytical RP-HPLC method for development and validation of pregabalin and methylcobalamine in combined capsule formulation. Appl Chem Res. 13, 85, (2010).

11. Mohan A J, Raj Kumar B, Bhavya T, Ashok Kumar A. RP-HPLC Method 
Development and validation for the simultaneous quantitative estimation of pregabalin, mecobalamin and alpha lipoic Acid in capsules. Int $J$ Pharm Pharmsci. 6, 270, (2014).

12. Gelani H D, Chauhan $\mathrm{P} P$, Shah $\mathrm{S}$ K. Practical Implication of Chromatographic Method for Estimation of Aceclofenac and Pregabalin in Bulk and Pharmaceutical Dosage Forms. Chromatography Research International. 5, (2014).
13. Pola L M, Sankar D G. Validated stability indicating RP-LC method for simultaneous quantitative estimation of aceclofenac and pregabalin in bulk drug and combined tablet dosage form. Int J Pharm. 5, 78, (2014).

14. Geneva: International Conference on Harmonization; ICH, Q2 (R1) Harmonised Tripartite Guideline. Validation of Analytical Procedures: Text and Methodology, 2005; pp. 1-13. 